\title{
Microwave synthesis, spectral, thermal, and antimicrobial activities of some transition metal complexes involving 5-bromosalicylaldehyde moiety
}

\author{
Rajendra K. Jain ${ }^{*}$ and A. P. Mishra
}

Department of Chemistry, Synthetic Inorganic \& Coordination Chemistry Laboratories, Dr. H. S. Gour Central University, Sagar M.P. 470 003, India

\begin{tabular}{l}
\hline A R T I C L E I N F O \\
\hline Article history: \\
Received May 30, 2012 \\
Received in Revised form \\
June 23, 2012 \\
Accepted 12 July2012 \\
Available online \\
14 July 2012 \\
\hline Keywords: \\
Microwave synthesis \\
5-Bromosalicylaldehyde \\
Aniline \\
Thermal analysis \\
Biological activity
\end{tabular}
\begin{abstract}
A B S T R A C T
The coordination complexes of $\mathrm{Co}(\mathrm{II}), \mathrm{Ni}(\mathrm{II})$ and $\mathrm{Cu}(\mathrm{II})$ derived from 5-bromosalicylidene-3,4dimethylaniline (BSMA) and 5-bromosalicylidene-3,4-dichloroaniline (BSCA) have been synthesized by conventional as well as microwave methods. These compounds have been characterized by elemental analysis, FT-IR, molar conductance, electronic spectra, ${ }^{1} \mathrm{H}-\mathrm{NMR}$, FAB-mass, ESR, magnetic susceptibility, electrical conductivity and thermal analysis. The complexes are coloured and stable in air. Analytical data revealed that all the complexes exhibited 1:2 (metal: ligand) ratio with coordination number 4 or 6 . IR data shows that the ligand coordinates with the metal ions in a bidentate manner through the phenolic oxygen and azomethine nitrogen. FAB-mass and thermal data show degradation pattern of the complexes. Solid state electrical conductivity studies reflect semiconducting nature of the complexes. The Schiff base and metal complexes show a good activity against the Gram-positive bacteria; Staphylococcus aureus and Gram-negative bacteria; Escherichia coli and fungi Aspergillus niger and Candida albicans.
\end{abstract}

(C) 2012 Growing Science Ltd. All rights reserved.

\section{Introduction}

Metal complexes have been receiving considerable attention for many years, due to their interesting characteristics in the field of material science and biological systems. Optoelectronic, electrical and magnetic properties of the metals and metalloids can be tailored by reacting them with different ligands. A large number of Schiff bases and their complexes may exhibit the properties liketo reversibly bind oxygen, transfer of an amino group, as nanoprecursors and varied complexing/redox ability. The Schiff bases have high affinity to chelate with the transition metal ions, hence are attracting attention due to potential applications in areas viz. biology, catalysis,

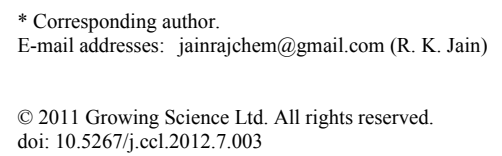


thermal, electrical, optical , magnetic etc. Metal complexes are suitable to molecular materials, on the basis of electronic properties associated with the metal center ${ }^{1-3}$.

Schiff base ligands containing $\mathrm{O}$ and $\mathrm{N}$ donor atoms play an important role in coordination chemistry related to catalysis and enzymatic reaction, magnetism and molecular architecture. Metal complexes with Schiff base ligands containing salicylaldehyde and its derivatives; have been extensively studied. Metal complexes with such ligands are quite common and also reflect their facile synthesis, accessibility of diverse structural modifications and wide applications in different fields, such as catalysis, biological systems and material chemistry ${ }^{4,5}$.

Microwave reactions under solvent free and less solvent conditions are attractive offering reduced pollution, low cost and offer high yields together with simplicity in processing and handling. The salient features of microwave approach are shorter reaction times, simple reaction conditions and enhancements in yields ${ }^{6-11}$.

In this study, we report the synthesis, physicochemical characterization and biological significances of $\mathrm{Co}(\mathrm{II}), \mathrm{Ni}(\mathrm{II})$ and $\mathrm{Cu}$ (II) complexes with ligands derived from 5-bromosalicylaldehyde with 3,4-dimethylaniline (BSMA) and 3,4-dichloroaniline (BSCA) (Fig. 1). The reaction was carried out by both conventional and microwave methods. The metal complexes formed with these two new ligands may be used as precursors for the synthesis of new compounds. Some of them may exhibit interesting physical, chemical and. biological properties.

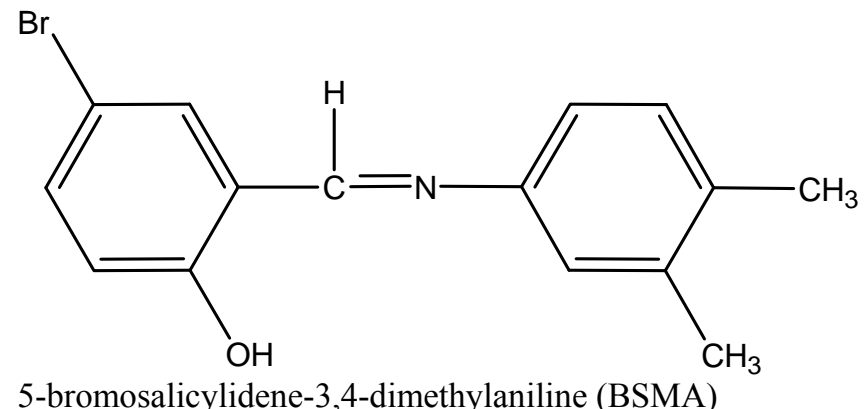

5-bromosalicylidene-3,4-dimethylaniline (BSMA)

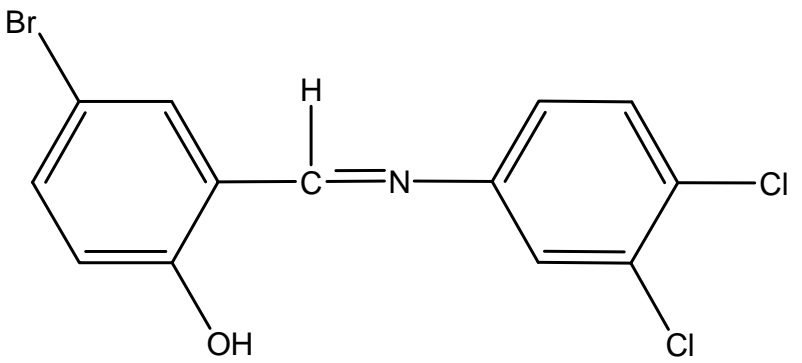

5-bromosalicylidene-3,4-dichloroaniline (BSCA)

Fig. 1. Structure of Schiff base ligands

\section{Results and discussion}

As a result of microwave assisted synthesis, it was observed that the reaction was completed in a short time with higher yields compared to the conventional method. In the microwave method homogeneity of reaction mixture was increased by the rotating of reaction platform tray.

All the metal complexes are coloured, solid and stable towards air and moisture at room temperature. They decompose on heating at high temperature and more or less soluble in common organic solvents. Comparative study results obtained by microwave assisted synthesis; versus conventional heating method are that some reactions which required 3.4-7.9 $\mathrm{h}$ by conventional method, was completed within 4-8 min by the microwave irradiation technique and yields have been improved from $66-78 \%$ to $81-88 \%$. The comparative results of microwave and conventional methods, with analytical and physical data of the compounds are given in the Table 1 . All the metal chelates have 1:2 (metal:ligand) stoichiometry. The observed molar conductance of the complexes in DMSO at room temperature is consistent with the non-electrolytic nature of the complexes. 
Table 1. The comparative results of conventional and microwave methods, analytical and physical data of the compounds

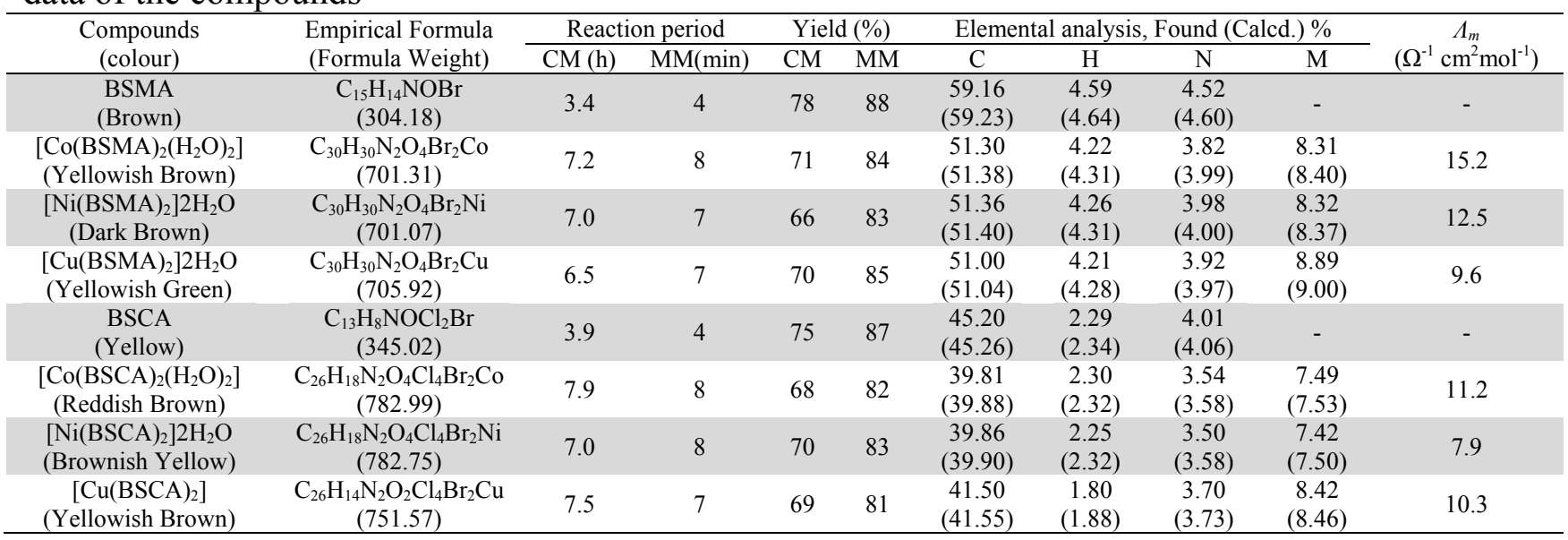

$\mathrm{CM}=$ Conventional Method; $\mathrm{MM}=$ Microwave Method

\section{FAB-mass spectra}

The FAB-mass spectra suggested that all the complexes have a monomeric nature. These complexes show molecular ion peaks in good agreement with the empirical formula suggested by elemental analyses. The FAB-mass of the $\left[\mathrm{Co}(\mathrm{BSCA})_{2}\left(\mathrm{H}_{2} \mathrm{O}\right)_{2}\right]$ complex exhibited the molecular ion $\left(\mathrm{M}^{+}\right)$peak at $m / z=702$ suggesting the monomeric nature of the complex. The other important peaks of appreciable intensity have been observed at $\mathrm{m} / \mathrm{z}$ values, obs.(calcd.) - 663(665), 606(605), 444(445), 298(295) and 116(119) suggesting the ion species after the successive fragmentation of different groups. The intensities of these peaks give the idea of the stabilities of the fragments. The $\mathrm{m} / \mathrm{z}$ value 702 corresponds to the nearest composition $\left[\mathrm{Co}(\mathrm{BSCA})_{2}\left(\mathrm{H}_{2} \mathrm{O}\right)_{2}\right]$ and 116 to Co metal with chelated $\mathrm{N}$ and $\mathrm{O}$ ligand moiety. The FAB-mass spectrum of the $\left[\mathrm{Ni}(\mathrm{BSCA})_{2}\right] 2 \mathrm{H}_{2} \mathrm{O}$ complex showed a characteristic molecular ion $\left(\mathrm{M}^{+}\right)$peak at $m / z=784$, which corresponds to the molecular weight of the complex for a monomeric structure. The mass spectrum shows multiple peaks representing successive degradation of the complex molecule by the formation of different fragments. The peaks of appreciable intensity have been observed at $\mathrm{m} / \mathrm{z}$ values, obs.(calcd.) $-784(783)$, 745(747), 587(587), 446(445), 296(295) and 118(119) suggesting the fragmentation pattern. The $\mathrm{m} / \mathrm{z}$ value 784 corresponds to the nearest composition of the $\left[\mathrm{Ni}(\mathrm{BSCA})_{2}\right] 2 \mathrm{H}_{2} \mathrm{O}$ and 118 corresponds to $\mathrm{Ni}$ metal with chelated $\mathrm{O}$ and $\mathrm{N}$ ligand moiety ${ }^{12,13}$.

\section{${ }^{1} H$-NMR spectra}

The proton NMR spectra of the Schiff base ligands were recorded in DMSO- $\mathrm{d}_{6}$ solution using TMS as internal standard. The ${ }^{1} \mathrm{H}-\mathrm{NMR}$ spectra of the BSMA and BSCA ligands showed multiplet at $\delta$ 7.127-7.652 and 7.232-7.874 ppm due to aromatic protons while the azomethine proton resonates as singlet at $\delta 8.461$ and $8.941 \mathrm{ppm}$. The phenolic $\mathrm{OH}$ groups have signals at $\delta 12.243$ and $12.854 \mathrm{ppm}$ which are disappeared on deutration ${ }^{14,15}$.

\section{IR spectra}

The data of the IR spectra of Schiff base ligand and their metal complexes are listed in Table 2. The IR spectra of the complexes were compared with those of the free ligand in order to determine the involvement of coordination sites in chelation. Characteristic peaks in the spectra of the ligands and complexes were considered and compared.

IR spectra of the BSMA and BSCA Schiff base ligands exhibited the most characteristic bands at $3312-3335 \mathrm{~cm}^{-1} v(\mathrm{O}-\mathrm{H}), 1620-1628 \mathrm{~cm}^{-1} v(\mathrm{C}=\mathrm{N}$, azomethine $)$ and $1248-1255 \mathrm{~cm}^{-1} v(\mathrm{C}-\mathrm{O})$. The 
ligand spectra showed bands at 3316-3304 and 1340-1348 $\mathrm{cm}^{-1}$ due to the stretching and deformation of the phenolic $\mathrm{OH}^{16}$. These are absent in the spectra of the complexes indicates the deprotonation of the hydroxyl group and co-ordination through oxygen. The band $1620-1628 \mathrm{~cm}^{-1}$ due to the azomethine group of the Schiff bases have shifted to lower frequency (1595-1605 $\mathrm{cm}^{-1}$ ) after complexation, indicating the bonding of nitrogen of the azomethine group to the metal ion and this can be explained by the donation of electrons from nitrogen to the empty d-orbital of the metal ion. The phenolic $v(\mathrm{C}-\mathrm{O})$ stretching vibration that appeared at $1248-1255 \mathrm{~cm}^{-1}$ in Schiff bases shift towards higher frequencies $\left(25-30 \mathrm{~cm}^{-1}\right)$ in the complexes. This shift confirms the participation of oxygen in the C-O-M bond. The appearance of broad bands around at $\left(3388-3420 \mathrm{~cm}^{-1}\right)$ in the spectra of complexes may be due to water molecules. But this band is not presented in the Cu(II)-BSCA, indicating that the absence of water molecules in $\mathrm{Cu}$ (II) complexes. In the low frequency region, a band at 812 and $800 \mathrm{~cm}^{-1}$ in $\mathrm{Co}(\mathrm{II})$-BSMA and $\mathrm{Co}(\mathrm{II})$-BSCA (OH rocking), respectively, in the complexes, suggest the presence of coordinated water molecules in these complexes. Two new bands appearing in the low frequency range $538-556 \mathrm{~cm}^{-1}$ and $488-496 \mathrm{~cm}^{-1}$ are assigned to $v(\mathrm{M}-\mathrm{O})$ and $v(\mathrm{M}-\mathrm{N})$, respectively ${ }^{17-19}$.

From this observation, it may be concluded that Schiff bases act as mono negative, bidentate coordinating through oxygen of phenolic $\mathrm{C}-\mathrm{O}$ group and nitrogen of $\mathrm{C}=\mathrm{N}$ group.

Table 2. Selected IR bands $\left(\mathrm{cm}^{-1}\right)$ of Schiff base ligands and their complexes

\begin{tabular}{lcccccc}
\hline Compound & $v(\mathrm{C}=\mathrm{N})$ & $v(\mathrm{O}-\mathrm{H})$ & $v(\mathrm{C}-\mathrm{O})$ & $\mathrm{H}_{2} \mathrm{O}$ & $v(\mathrm{M}-\mathrm{O})$ & $v(\mathrm{M}-\mathrm{N})$ \\
\hline BSMA & 1620 & 3312 & 1248 & - & - & - \\
{$\left[\mathrm{Co}(\mathrm{BSMA})_{2}\left(\mathrm{H}_{2} \mathrm{O}\right)_{2}\right]$} & 1600 & - & 1275 & 3388,812 & 538 & 488 \\
{$\left[\mathrm{Ni}(\mathrm{BSMA})_{2}\right] 2 \mathrm{H}_{2} \mathrm{O}$} & 1598 & - & 1279 & 3420 & 540 & 489 \\
{$\left[\mathrm{Cu}(\mathrm{BSMA})_{2}\right] 2 \mathrm{H}_{2} \mathrm{O}$} & 1595 & - & 1278 & 3390 & 545 & 495 \\
$\mathrm{BSCA}$ & 1628 & 3335 & 1255 & - & - & - \\
{$\left[\mathrm{Co}(\mathrm{BSCA})_{2}\left(\mathrm{H}_{2} \mathrm{O}\right)_{2}\right]$} & 1605 & - & 1285 & 3375,800 & 556 & 492 \\
{$\left[\mathrm{Ni}(\mathrm{BSCA})_{2}\right] 2 \mathrm{H}_{2} \mathrm{O}$} & 1599 & - & 1282 & 3400 & 552 & 496 \\
{$\left[\mathrm{Cu}(\mathrm{BSCA})_{2}\right]$} & 1604 & - & 1280 & - & 554 & 490 \\
\hline
\end{tabular}

\section{Electronic spectra and magnetic moment}

The electronic spectral data of the metal complexes in DMSO solution are given in Table 3. The nature of the ligand field around the metal ion has been deduced from the electronic spectra. The electronic spectra of $\left[\mathrm{Co}(\mathrm{BSMA})_{2}\left(\mathrm{H}_{2} \mathrm{O}\right)_{2}\right]$ and $\left[\mathrm{Co}(\mathrm{BSCA})_{2}\left(\mathrm{H}_{2} \mathrm{O}\right)_{2}\right]$ exhibited three bands in the region of 9425-9750 $\mathrm{cm}^{-1}, 15257-15748 \mathrm{~cm}^{-1}$ and 19612-19607 $\mathrm{cm}^{-1}$ which have tentatively been assigned to ${ }^{4} \mathrm{~T}_{1 \mathrm{~g}} \rightarrow{ }^{4} \mathrm{~T}_{2 \mathrm{~g}}(\mathrm{~F})\left(v_{1}\right),{ }^{4} \mathrm{~T}_{1 \mathrm{~g}} \rightarrow{ }^{4} \mathrm{~A}_{2 \mathrm{~g}}(\mathrm{~F})\left(v_{2}\right)$ and ${ }^{4} \mathrm{~T}_{1 \mathrm{~g}} \rightarrow{ }^{4} \mathrm{~T}_{1 \mathrm{~g}}(\mathrm{P})\left(v_{3}\right)$ transitions, respectively. The values of magnetic moment for these complexes are 5.08 and 5.12 B.M., respectively. Thus the octahedral geometry has been suggested for these complexes.

The absorption spectra of the $\left[\mathrm{Ni}(\mathrm{BSMA})_{2}\right] \cdot 2 \mathrm{H}_{2} \mathrm{O}$ and $\left[\mathrm{Ni}(\mathrm{BSCA})_{2}\right] \cdot 2 \mathrm{H}_{2} \mathrm{O}$ exhibited bands at $12112-12689 \mathrm{~cm}^{-1}$ and $21648-22152 \mathrm{~cm}^{-1}$, which have tentatively been assigned to the transitions ${ }^{1} \mathrm{~A}_{1 \mathrm{~g}} \rightarrow{ }^{1} \mathrm{E}_{\mathrm{g}}\left(v_{1}\right)$ and ${ }^{1} \mathrm{~A}_{1 \mathrm{~g}} \rightarrow{ }^{1} \mathrm{~B}_{2 \mathrm{~g}}\left(v_{2}\right)$, respectively, these are diamagnetic complex, therefore square planar geometry has been suggested. The electronic spectra of the $\left[\mathrm{Cu}(\mathrm{BSMA})_{2}\right] \cdot 2 \mathrm{H}_{2} \mathrm{O}$ and $\left[\mathrm{Cu}(\mathrm{BSCA})_{2}\right]$ showed two bands at $12879-13698 \mathrm{~cm}^{-1}$ and $18542-18210 \mathrm{~cm}^{-1}$ assignable to ${ }^{2} \mathrm{~B}_{1 \mathrm{~g}} \rightarrow{ }^{2} \mathrm{~B}_{2 \mathrm{~g}}$ and ${ }^{2} \mathrm{~B}_{1 \mathrm{~g}} \rightarrow{ }^{2} \mathrm{E}_{\mathrm{g}}$ transitions, respectively, Since the value of magnetic moment for these complexes found 1.92 and 1.97 B.M.; therefore square planar geometry has been suggested for these $\mathrm{Cu}(\mathrm{II})$ complex $^{20-22}$. 
Table 3. Magnetic moment values and electronic spectral data of complexes

\begin{tabular}{|c|c|c|c|}
\hline Complex & $\mu_{e f f}$ (B.M.) & $\lambda_{\max }\left(\mathrm{cm}^{-1}\right)$ & Band assignments \\
\hline \multirow{3}{*}[\mathrm{Co}(\mathrm{BSMA})_{2}(\mathrm{H}_{2}\mathrm{O})_{2}]{} & \multirow{3}{*}{5.08} & 9425 & ${ }^{4} \mathrm{~T}_{1 \mathrm{~g}} \rightarrow{ }^{4} \mathrm{~T}_{2 \mathrm{~g}}(\mathrm{~F})$ \\
\hline & & 15257 & ${ }^{4} \mathrm{~T}_{1 \mathrm{~g}} \rightarrow{ }^{4} \mathrm{~A}_{2 \mathrm{~g}}(\mathrm{~F})$ \\
\hline & & 19612 & ${ }^{4} \mathrm{~T}_{1 \mathrm{~g}} \rightarrow{ }^{4} \mathrm{~T}_{1 \mathrm{~g}}(\mathrm{P})$ \\
\hline \multirow{3}{*}[\mathrm{Ni}(\mathrm{BSMA})_{2}]{$2 \mathrm{H}_{2} \mathrm{O}$} & \multirow{3}{*}{ Dia. } & 12112 & ${ }^{1} \mathrm{~A}_{1 \mathrm{~g}} \rightarrow{ }^{1} \mathrm{E}_{\mathrm{g}}$ \\
\hline & & 21648 & ${ }^{1} \mathrm{~A}_{1 \mathrm{~g}} \rightarrow{ }^{1} \mathrm{~B}_{2 \mathrm{~g}}$ \\
\hline & & - & ${ }^{1} \mathrm{~A}_{1 \mathrm{~g}} \rightarrow{ }^{1} \mathrm{~B}_{1 \mathrm{~g}}$ \\
\hline \multirow[t]{2}{*}[\mathrm{Cu}(\mathrm{BSMA})_{2}]{$2 \mathrm{H}_{2} \mathrm{O}$} & \multirow{2}{*}{1.92} & 12879 & ${ }^{2} \mathrm{~B}_{1 \mathrm{~g}} \rightarrow{ }^{2} \mathrm{~B}_{2 \mathrm{~g}}$ \\
\hline & & 18542 & ${ }^{2} \mathrm{~B}_{1 \mathrm{~g}} \rightarrow{ }^{2} \mathrm{E}_{\mathrm{g}}$ \\
\hline \multirow{3}{*}[\mathrm{Co}(\mathrm{BSCA})_{2}(\mathrm{H}_{2}\mathrm{O})_{2}]{} & \multirow{3}{*}{5.12} & 9750 & ${ }^{4} \mathrm{~T}_{1 \mathrm{~g}} \rightarrow{ }^{4} \mathrm{~T}_{2 \mathrm{~g}}(\mathrm{~F})$ \\
\hline & & 15748 & ${ }^{4} \mathrm{~T}_{1 \mathrm{~g}} \rightarrow{ }^{4} \mathrm{~A}_{2 \mathrm{~g}}(\mathrm{~F})$ \\
\hline & & 19607 & ${ }^{4} \mathrm{~T}_{1 \mathrm{~g}} \rightarrow{ }^{4} \mathrm{~T}_{1 \mathrm{~g}}(\mathrm{P})$ \\
\hline \multirow{3}{*}[\mathrm{Ni}(\mathrm{BSCA})_{2}]{$2 \mathrm{H}_{2} \mathrm{O}$} & \multirow{3}{*}{ Dia. } & 12689 & ${ }^{1} \mathrm{~A}_{1 \mathrm{~g}} \rightarrow{ }^{1} \mathrm{E}_{\mathrm{g}}$ \\
\hline & & 22152 & ${ }^{1} \mathrm{~A}_{1 \mathrm{~g}} \rightarrow{ }^{1} \mathrm{~B}_{2 \mathrm{~g}}$ \\
\hline & & - & ${ }^{1} \mathrm{~A}_{1 \mathrm{~g}} \rightarrow{ }^{1} \mathrm{~B}_{1 \mathrm{~g}}$ \\
\hline \multirow{2}{*}[\mathrm{Cu}(\mathrm{BSCA})_{2}]{} & \multirow{2}{*}{1.97} & 13698 & ${ }^{2} \mathrm{~B}_{1 \mathrm{~g}} \rightarrow{ }^{2} \mathrm{~B}_{2 \mathrm{~g}}$ \\
\hline & & 18210 & ${ }^{2} \mathrm{~B}_{1 \mathrm{~g}} \rightarrow{ }^{2} \mathrm{E}_{\mathrm{g}}$ \\
\hline
\end{tabular}

\section{ESR spectra}

The ESR spectra of $\mathrm{Cu}(\mathrm{II})$ provide information about the extent of the delocalization of unpaired electron. The X-band ESR spectra of $\mathrm{Cu}$ (II) complexes were recorded in the solid state at room temperature and their $g_{\|}, g_{\perp}, \Delta g, g_{a v}$ and $G$ have been calculated. The values of ESR parameters $g_{\|}$, $g_{\perp}, g_{a v}, \Delta g$ and $G$ for $\mathrm{Cu}(\mathrm{II})$ complex of BSMA are 2.2225, 2.1132, 2.1496, 0.1093and 1.9856 respectively. Similarly, the corresponding values for $\mathrm{Cu}(\mathrm{II})$ complex of BSCA are 2.2125, 2.1332, $2.1596,0.0793$ and 1.6058 respectively. ESR spectra of the complexes revealed two $g$ values $(g \|$ and $g \perp$ ). Since the $g \|$ and $g \perp$ values are closer to 2 and $g \|^{>} g \perp$ suggesting a tetragonal distortion around the $\mathrm{Cu}(\mathrm{II})$ ion. The trend $g \|>g_{\perp}>g_{e}(2.0023)$ shows that the unpaired electron is localized in $\mathrm{dx}_{\mathrm{X}}^{2}-\mathrm{Y}^{2}$ orbital in the ground state of $\mathrm{Cu}(\mathrm{II})$ and spectra are characteristic of axial symmetry. The $g \|>2.3$ is characteristic of an ionic environment and $g_{\|}<2.3$ indicates a covalent environment in metal ligand bonding. The $g_{\|}$values for the complexes are (2.2225-2.2125) less than 2.3 suggesting, the environment is covalent.

The exchange coupling interaction between two $\mathrm{Cu}(\mathrm{II})$ ions is explained by Hathaway expression $G=\left(g_{\|}-2.0023\right) /\left(g_{\perp-2.0023)}\right.$. According to Hathaway, if the value $G$ is greater than four $(\mathrm{G}>4.0)$, the exchange interaction is negligible; whereas when the value of $G$ is less than four $(\mathrm{G}<4.0)$ a considerable exchange coupling is present in solid complex. The $G$ values for the $\mathrm{Cu}$ (II) complexes (1.9856-1.6058) are less than four indicating, considerable exchange interaction in the complexes ${ }^{23,24}$.

\section{Thermal analyses}

The thermal behavior of metal complexes shows that the hydrated complexes lose molecules of hydration first; followed by decomposition of ligand molecules in the subsequent steps. The results show good agreement with the suggested formulae from the analytical data (Table 1).

The thermal degradation behaviour of the Ni(II) complex of BSMA has been studied by thermogravimetric analysis. The TG curve of the complex shows that the complex starts to decompose at $70{ }^{\circ} \mathrm{C}$. Elimination of lattice water molecules has been observed on increasing the temperature up to $115^{\circ} \mathrm{C}$ (remaining wt.\%, obs./calcd., 95.62/94.86). The complex does not show any 
loss in weight between 115 and $190{ }^{\circ} \mathrm{C}$. After $190{ }^{\circ} \mathrm{C}$, a loss in weight has been observed in general up to $380{ }^{\circ} \mathrm{C}$ corresponding to the loss of partially decomposed ligand part from the complex (remaining wt.\%, obs./calcd., 56.50/55.82). Above $420{ }^{\circ} \mathrm{C}$, loss in weight has been occurs up to 580 ${ }^{\circ} \mathrm{C}$. This indicates the elimination of the remaining thermally degradable part of the complex. After $580{ }^{\circ} \mathrm{C}$ a horizontal curve has been observed which corresponds to a mixture of metal oxide as an ultimate pyrolysis product (remaining wt.\%, obs./calcd., 22.75/21.50).

The TG curve of the Co(II) complex of BSCA shows (Fig. 2) that the complex is stable upto 120 ${ }^{\circ} \mathrm{C}$. This indicates the absence of lattice water molecule in the complex. On increasing the temperature decomposition started between the temperature range $120-200{ }^{\circ} \mathrm{C}$, corresponding to elimination of two coordinated water molecules (Remaining Wt.\%, Obs./Calcd., 96.42/95.40). After this temperature, a loss in weight has been observed in general up to $400{ }^{\circ} \mathrm{C}$ corresponding to the loss of partially decomposed ligand part from the complex (Remaining Wt.\%, Obs./Calcd., 52.12/50.50). Above this temperature, a weight loss has been occurred upto $630^{\circ} \mathrm{C}$. This indicates the elimination of the remaining thermally degradable part of the complex. After $630^{\circ} \mathrm{C}$, a plateau has been observed which corresponds to metal oxide as an ultimate pyrolysis product (Remaining Wt.\%, Obs./Calcd., $24.84 / 23.70)^{25,26}$. The thermal analysis evaluates the thermal stability of the metal complexes, this study also helped to characterize the metal complexes.

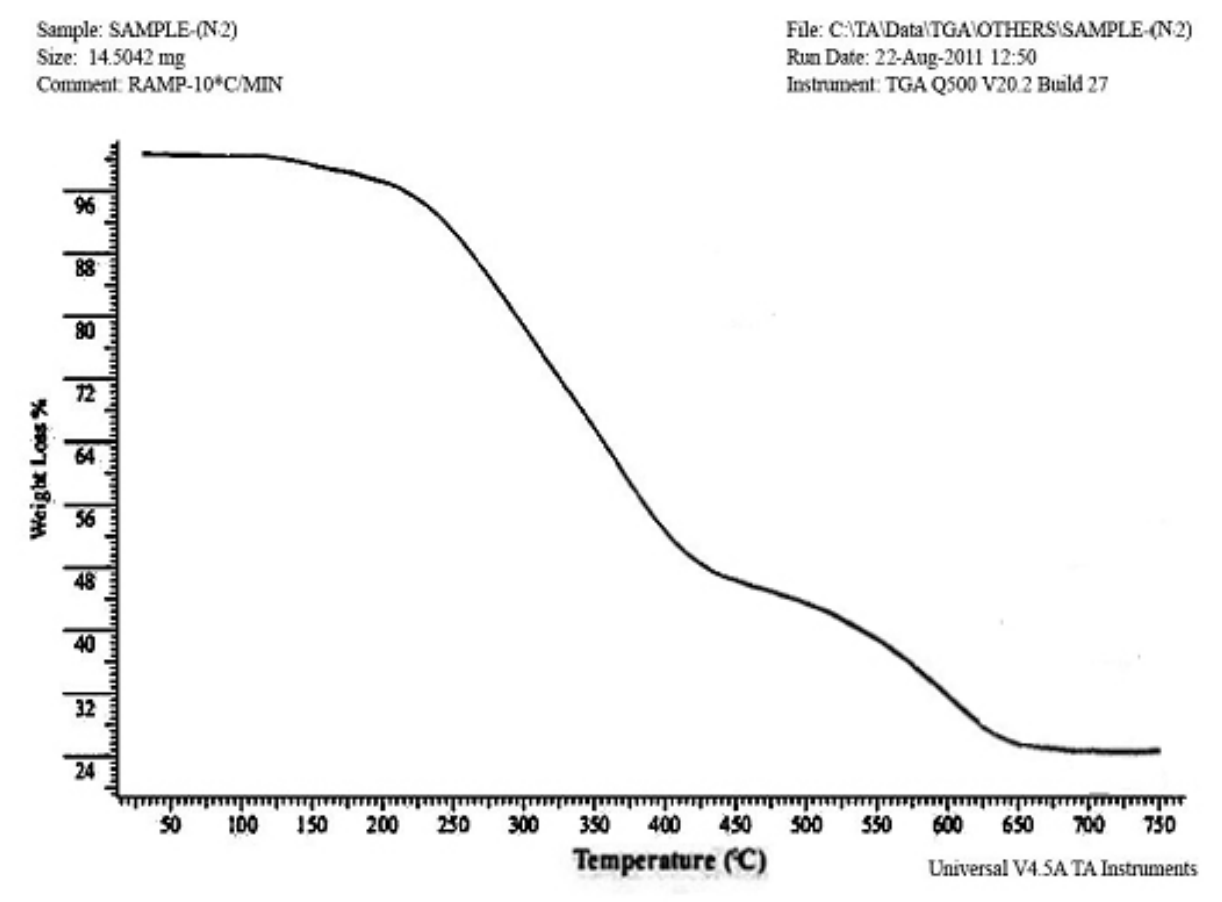

Fig. 2. TG curve of $\left[\mathrm{Co}(\mathrm{BSCA})_{2}\left(\mathrm{H}_{2} \mathrm{O}\right)_{2}\right]$ complex Electrical conductivity

The temperature dependence of the solid state conductivity $(\sigma)$ of the compounds in their compressed pellet form have been measured at fixed frequency $1 \mathrm{KHz}$ in the temperature range 297$397 \mathrm{~K}$. The values of the solid state electrical conductivity of the Schiff base and its complexes increase with increasing temperature and decrease upon cooling over the studies temperature range indicating its semiconducting behaviour. The general behavior of electrical conductivity follows the Arrhenius equation:

$$
\sigma=\sigma_{o} \exp (-E a / K T)
$$

where $E a$ is the thermal activation energy of conduction, $\sigma_{o}$ is the conductivity constant and $\mathrm{K}$ is the Boltzman constant. The lots of $\sigma$ vs $1000 / T$ for all the compounds are found to be linear over a studied temperature range. The room temperature electrical conductivity of all the compounds lies in the range $4.35 \times 10^{-7}-7.26 \times 10^{-8} \mathrm{ohm}^{-1} \mathrm{~cm}^{-1}$. These values show their semi-conducting nature. The electrical conductivity at room temperature for the complexes of BSMA are $\mathrm{Co}>\mathrm{Cu}>\mathrm{Ni}$ and for the 
metal complexes of BSCA are $\mathrm{Co}>\mathrm{Cu}>\mathrm{Ni}$. The activation energy of the compound lies in the range $0.218-0.787 \mathrm{eV}^{27,28}$. The confirmation of the temperature dependence conductivity of the compounds was also checked by the repeating of the conductivity measurements.

\section{Antimicrobial activities}

The in vitro antimicrobial activity of the synthesized Schiff base ligands and their corresponding metal complexes on selected bacteria $E$. coli and $S$. aureus and two fungi A. niger and C. albicans was carried out. All of the tested compounds showed good biological activity against microorganism. The bactericidal and fungicidal investigation data of the compounds are summarized in Tables 4 and 5. Moreover, all the complexes are moderatively active as compared to the standard bactericide and fungicide (Streptomycin and Miconazole). A comparative study of the ligands and their transition metal complexes indicates that the complexes are more active than their respective ligands, the activity increases upon coordination. The increased activity of the metal chelates than those of the ligands can be explained on the basis of Overtone's concept and Chelation theory. On chelation, the polarity of the metal ion will be reduced to a greater extent due to the overlap of the ligand orbital and partial sharing of the positive charge of the metal ion with donor groups. Further, it increases the delocalization of the $\pi$-electrons over the whole chelating ring and enhances the penetration of the complexes into lipid membranes and blocking of the metal binding sites in the enzymes of microorganisms. There are other factors also, which increase the activity viz. solubility, lipophilicity/ hydrophilicity, conductivity and M-L bond length ${ }^{29-32}$.

Table 4. Antibacterial screening data for the ligands and their complexes

\begin{tabular}{|c|c|c|c|c|c|c|c|c|c|c|c|c|}
\hline \multirow{3}{*}{ Compound } & \multicolumn{6}{|c|}{ E. coli } & \multicolumn{6}{|c|}{ S. aureus } \\
\hline & \multicolumn{3}{|c|}{$\begin{array}{c}\text { Diameter of inhibition } \\
\text { zone (in } \mathrm{mm} \text { ) }\end{array}$} & \multicolumn{3}{|c|}{$\mathrm{b}_{\%} \%$ Activity index } & \multicolumn{3}{|c|}{$\begin{array}{c}\text { Diameter of inhibition } \\
\text { zone (in mm) }\end{array}$} & \multicolumn{3}{|c|}{ b\% Activity index } \\
\hline & $25^{\mathrm{a}}$ & $50^{\mathrm{a}}$ & $100^{\mathrm{a}}$ & $25^{\mathrm{a}}$ & $50^{\mathrm{a}}$ & $100^{\mathrm{a}}$ & $25^{\mathrm{a}}$ & $50^{\mathrm{a}}$ & $100^{\mathrm{a}}$ & $25^{\mathrm{a}}$ & $50^{\mathrm{a}}$ & $100^{\mathrm{a}}$ \\
\hline BSMA & 15 & 17 & 20 & 68 & 71 & 71 & 13 & 16 & 18 & 72 & 73 & 75 \\
\hline$\left[\mathrm{Co}(\mathrm{BSMA})_{2}\left(\mathrm{H}_{2} \mathrm{O}\right)_{2}\right]$ & 22 & 24 & 27 & 100 & 100 & 96 & 18 & 20 & 22 & 100 & 91 & 92 \\
\hline$\left[\mathrm{Ni}(\mathrm{BSMA})_{2}\right] 2 \mathrm{H}_{2} \mathrm{O}$ & 16 & 20 & 22 & 73 & 83 & 79 & 14 & 18 & 20 & 78 & 82 & 83 \\
\hline$\left[\mathrm{Cu}(\mathrm{BSMA})_{2}\right] 2 \mathrm{H}_{2} \mathrm{O}$ & 20 & 22 & 26 & 91 & 92 & 93 & 17 & 20 & 24 & 94 & 91 & 100 \\
\hline $\mathrm{BSCA}$ & 14 & 16 & 18 & 64 & 67 & 64 & 12 & 14 & 16 & 67 & 64 & 67 \\
\hline$\left[\mathrm{Co}(\mathrm{BSCA})_{2}\left(\mathrm{H}_{2} \mathrm{O}\right)_{2}\right]$ & 20 & 21 & 23 & 91 & 88 & 82 & 17 & 20 & 21 & 94 & 91 & 88 \\
\hline$\left[\mathrm{Ni}(\mathrm{BSCA})_{2}\right] 2 \mathrm{H}_{2} \mathrm{O}$ & 16 & 18 & 20 & 73 & 75 & 71 & 13 & 16 & 18 & 72 & 73 & 75 \\
\hline$\left[\mathrm{Cu}(\mathrm{BSCA})_{2}\right]$ & 20 & 23 & 26 & 91 & 96 & 93 & 15 & 18 & 21 & 83 & 82 & 88 \\
\hline $\begin{array}{l}\text { Streptomycin } \\
\text { (Standard) }\end{array}$ & 22 & 24 & 28 & 100 & 100 & 100 & 18 & 22 & 24 & 100 & 100 & 100 \\
\hline
\end{tabular}

Table 5. Antifungal screening data for the ligands and their complexes

\begin{tabular}{lcccccc}
\hline \multirow{2}{*}{ Compound } & \multicolumn{3}{c}{ A. niger } & \multicolumn{3}{c}{ C. albicans } \\
\cline { 2 - 7 } & \multicolumn{2}{c}{ Diameter of inhibition zone } & (in mm) & Diameter of inhibition zone & (in mm) \\
\cline { 2 - 7 } & $25^{\mathrm{a}}$ & $50^{\mathrm{a}}$ & $100^{\mathrm{a}}$ & $25^{\mathrm{a}}$ & $50^{\mathrm{a}}$ & $100^{\mathrm{a}}$ \\
\hline BSMA & 12 & 15 & 20 & 14 & 18 & 20 \\
{$\left[\mathrm{Co}(\mathrm{BSMA})_{2}\left(\mathrm{H}_{2} \mathrm{O}\right)_{2}\right]$} & 16 & 20 & 25 & 15 & 18 & 24 \\
{$\left[\mathrm{Ni}(\mathrm{BSMA})_{2}\right] 2 \mathrm{H}_{2} \mathrm{O}$} & 15 & 20 & 24 & 16 & 18 & 23 \\
{$\left[\mathrm{Cu}(\mathrm{BSMA})_{2}\right] 2 \mathrm{H}_{2} \mathrm{O}$} & 18 & 24 & 27 & 17 & 20 & 25 \\
$\mathrm{BSCA}$ & 13 & 17 & 22 & 14 & 16 & 20 \\
{$\left[\mathrm{Co}(\mathrm{BSCA})_{2}\left(\mathrm{H}_{2} \mathrm{O}\right)_{2}\right]$} & 18 & 22 & 28 & 20 & 22 & 28 \\
{$\left[\mathrm{Ni}(\mathrm{BSCA})_{2}\right] 2 \mathrm{H}_{2} \mathrm{O}$} & 16 & 19 & 24 & 16 & 18 & 22 \\
{$\left[\mathrm{Cu}(\mathrm{BSCA})_{2}\right]$} & 18 & 23 & 28 & 19 & 21 & 26 \\
Miconazole $($ Standard $)$ & 20 & 25 & 30 & 22 & 24 & 29 \\
\hline${ }^{\mathrm{a}} \mathrm{Con}$
\end{tabular}

${ }^{\mathrm{a}}$ Concentration in ppm 


\section{Conclusions}

In the present research studies, our efforts were to synthesize and characterize some new compounds from the conventional as well as microwave methods. Microwave method has been considered a green chemical route. These synthesized compounds were characterized by various physicochemical and spectral analyses. In course of microwave assisted synthesis, it was observed that the reaction time decreased from hours to minutes and availability of the product with better yield as compared to the conventional method. Use of solvent is also minimized. The synthesized Schiff base ligands bind with the metal ions in a bidentate manner, with ON donor sites of deprotonated phenolic-O and azomethine-N. The ${ }^{1} \mathrm{H}-\mathrm{NMR}$ data suggest that both the Schiff base ligand deprotonated after complexation. Such metal complexes may be of stereoselective and stereoactive in nature to be applicable for various catalytic reactions. Thermogravimetric studies reflect their thermal stability. The antimicrobial data showed that the metal complexes to be more biologically active compared to those parent Schiff base ligands against all pathogenic species. Such studies may assist to search some novel chemotherapeutics to answer the emerging problem of drug resistance in health sciences.

\section{Acknowledgements}

We are thankful to I.I.T. Mumbai for ESR analysis. We also acknowledge SAIF, CDRI Lucknow for micro analysis and spectral analysis. Thanks are also due to the Head, Department of Chemistry, Botany and Physics, Dr. Hari Singh Gour University, Sagar (M.P.) for providing Laboratory facilities.

\section{Experimental}

\section{Materials}

All the used chemicals and solvents were of Anal R grade. All the reagents used for the preparation of the Schiff bases were obtained from Sigma Aldrich. Metal salts were purchased from Loba Chemie.

\section{Physical measurements}

Elemental analyses were performed on an Elemental Vario EL III Carlo Erba 1108 analyzer. FAB-mass spectra were recorded on a JEOL SX 102/DA 6000. Electronic spectra (in DMSO) were recorded on Perkin Elmer Lambda-2B-spectrophotometer. Molar conductance measurements were conducted using $10^{-3} \mathrm{M}$ solution of the complexes in DMSO on Elico-CM 82 Conductivity Bridge at room temperature. Magnetic susceptibility measurements were carried out on a Gouy balance at room temperature using $\mathrm{Hg}\left[\mathrm{Co}(\mathrm{SCN})_{4}\right]$ as the calibrant.

FT-IR spectra were recorded in $\mathrm{KBr}$ pellet on a Perkin Elmer RX1 spectrophotometer in wave number region 4000-400 $\mathrm{cm}^{-1}$. ${ }^{1} \mathrm{H}$ NMR spectra were recorded on a JEOL AL300 FTNMR spectrometer employing TMS as internal reference and DMSO- $\mathrm{d}_{6}$ as solvent. X-band EPR spectra were recorded on a Varian E-112 spectrometer at room temperature operating at the X-band region with $100 \mathrm{kHz}$ modulation frequency, $5 \mathrm{mw}$ microwave power and $1 \mathrm{G}$ modulation amplitude using TCNE as the internal standard. Thermogravimetric analysis was carried out under atmospheric condition with a heating rate $10^{\circ} \mathrm{C} \mathrm{min}^{-1}$ on TGA Q500 universal V4.5A TA instrument. The solid state electrical conductivity has been measured by impedance spectroscopic method using HIOKI 3532-50 LCR Hitester at fixed frequency $1 \mathrm{kHz}$ in the temperature range of 297-397 K. Microwave assisted synthesis were carried out in open glass vessel on a modified microwave oven model 2001 ETB with rotating tray and a power source $230 \mathrm{~V}$, microwave energy output $800 \mathrm{~W}$ and microwave frequency $2450 \mathrm{MHz}$. A thermocouple device was used to monitor the temperature inside the vessel 
of the microwave. The microwave reactions were performed using on/off cycling to control the temperature.

\section{Biological activity}

The in-vitro biological activity of the investigated Schiff base and their metal complexes was tested against the bacteria Escherichia coli and Staphylococcus aureus by disc diffusion method using nutrient agar as medium and streptomycin as control. The antifungal activities of the compounds were also tested by the Well diffusion method against the fungi Aspergillus niger and Candida albicans, on potato dextrose agar as the medium and miconazole as control. Each of the compounds was dissolved in DMSO and solutions of different concentrations (25, 50 and $100 \mathrm{ppm})$ were prepared separately. In a typical procedure, a well was made on agar medium inoculated with microorganism. The well was filled with the test solution using a micropipette and the plate was incubated $24 \mathrm{~h}$ for bacteria at $37^{\circ} \mathrm{C}$ and $72 \mathrm{~h}$ for fungi at $30^{\circ} \mathrm{C}$. During this period, the test solution diffused and the growth of the inoculated microorganism was affected. The inhibition zone was developed, at which the concentration was noted. All determinations were performed in thrice.

\section{Conventional method for the synthesis of Schiff bases}

BSMA and BSCA Schiff bases were synthesized by the condensation of 1:1 ratio of 5bromosalicylaldehyde with 3,4-dimethylaniline and 3,4-dichloroaniline dissolved in ethanol. The resulting reaction mixture was refluxed for 3-4 $\mathrm{h}$ and then allowed to cool overnight. The coloured solid precipitate of Schiff base obtained was filtered, washed with cold ethanol and finally recrystallized from ethanol and ether and dried in air at room temperature and preserved in a $\mathrm{CaCl}_{2}$ desiccator. The purity of synthesized compounds was checked by TLC using silica gel G (BSMA Yield: $78 \%$; BSCA - 75\%).

\section{Microwave method for the synthesis of Schiff bases}

The equimolar (1:1) ratio of 5-bromosalicylaldehyde with 3,4-dimethylaniline and 3,4dichloroaniline were mixed thoroughly in a grinder. The reaction mixture was then irradiated by the microwave oven by taking 3-4 mL of dry ethanol as a solvent. The reaction was completed in a short time (4-5 min) with higher yields. The resulting product was then recrystallized with ethanol and finally dried under reduced pressure over anhydrous $\mathrm{CaCl}_{2}$ in a desiccator. The progress of the reaction and purity of the product was monitored by TLC using silica gel G (yield: $87-88 \%$ ).

\section{Conventional method for the synthesis of metal complexes}

The metal complexes were prepared by the mixing of $(50 \mathrm{~mL})$ ethanolic solution of $\mathrm{CoCl}_{2} \cdot 6 \mathrm{H}_{2} \mathrm{O} / \mathrm{NiCl}_{2} \cdot 6 \mathrm{H}_{2} \mathrm{O} / \mathrm{CuCl}_{2} \cdot 2 \mathrm{H}_{2} \mathrm{O}$ with the $(50 \mathrm{~mL})$ ethanolic solution of Schiff bases (BSMA/BSCA) (Figs. 3 and 4) in 1:2 (metal:ligand) ratio. The resulting mixture was refluxed on water bath for 6-8 h. A coloured product appeared on standing and cooling the above solution. The precipitated complex was filtered, washed with ether and recrystallized with ethanol several times and dried under the reduced pressure over anhydrous $\mathrm{CaCl}_{2}$ in a desiccator. It was further dried in electric oven at $50-70^{\circ} \mathrm{C}$ (yield: $67-71 \%$ ).

\section{Microwave method for the synthesis of metal complexes}

The ligand and the metal salts were mixed in 1:2 (metal:ligand) ratio in a grinder. The reaction mixture was then irradiated by the microwave oven by taking 3-5 $\mathrm{mL}$ of dry ethanol as a solvent. The reaction was completed in a short time (6-8 min) with higher yields. The resulting product was then recrystallized with ethanol and ether and finally dried under reduced pressure over anhydrous $\mathrm{CaCl}_{2}$ in a desiccator. The progress of the reaction and purity of the product was monitored by TLC using silica gel G (yield: 81-84\%). 


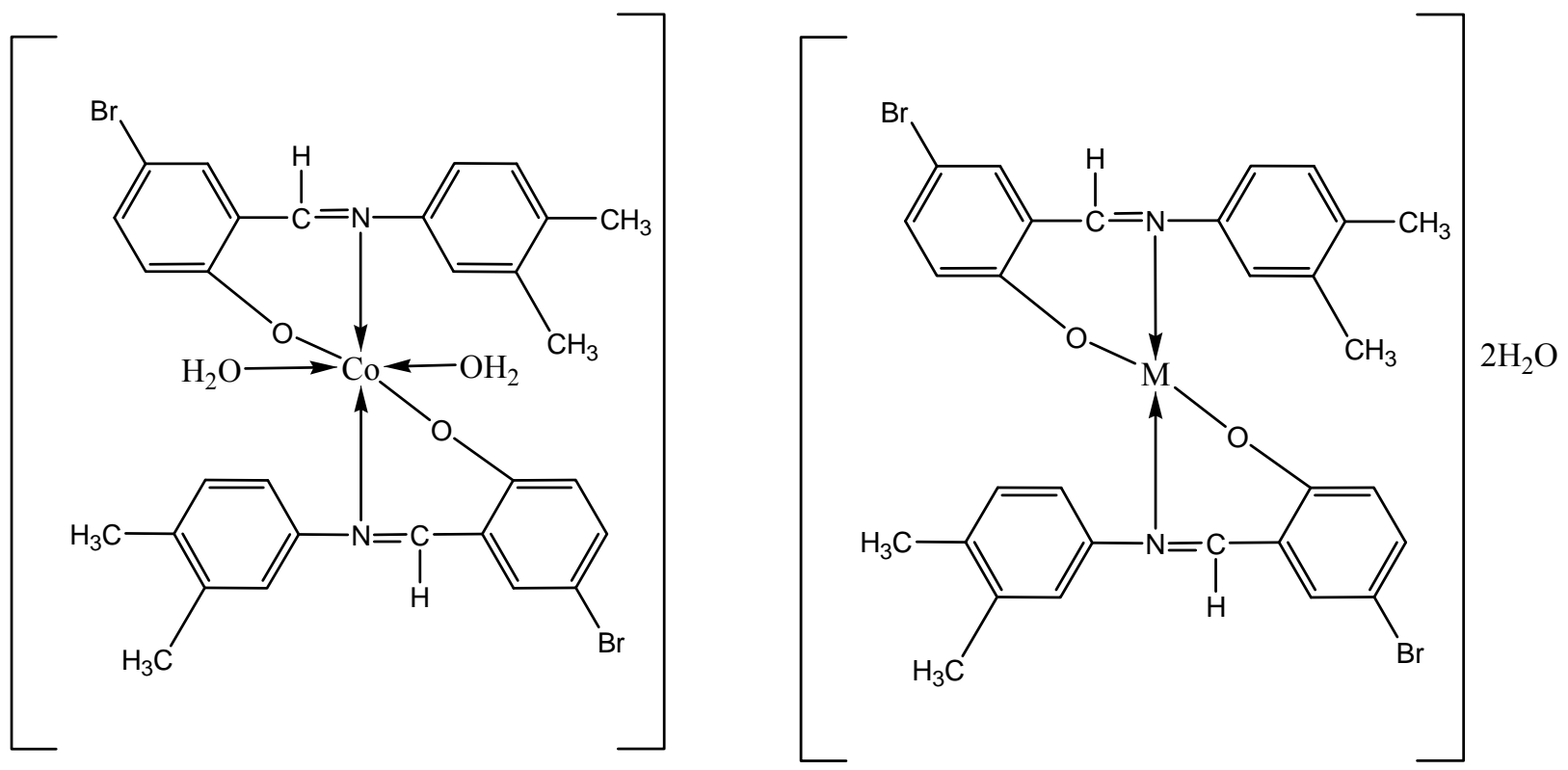

Fig. 3. Proposed structures of metal complexes of BSMA

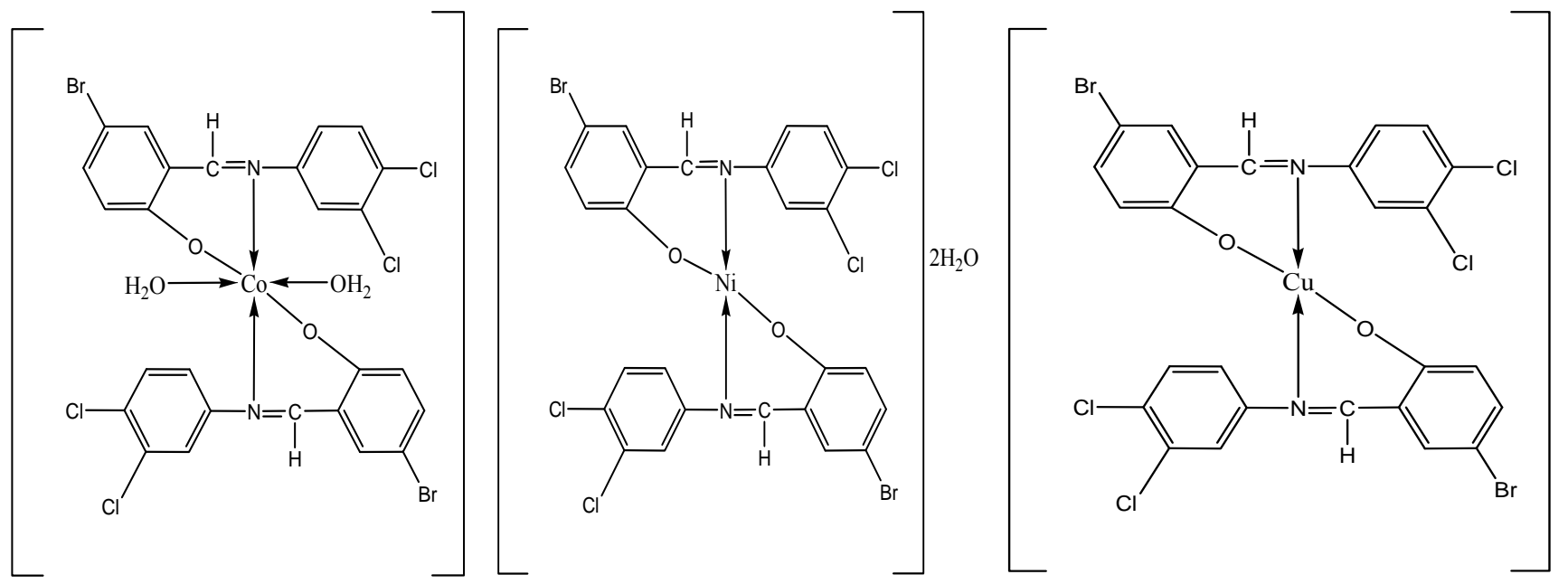

Fig. 4. Proposed structures of metal complexes of BSCA

\section{References}

1. Shukla, D, Gupta, L. K., and Chandra, S. (2008) Spectroscopic studies on chromium(III), manganese(II), cobalt(II), nickel(II) and copper(II) complexes with hexadentate nitrogen-sulfur donor [N2S4] macrocyclic ligand. Spectrochim. Acta, 71A, 746-750.

2. Spinu, C., Kriza, A., and Spinu, L. (2001) Studies on N-[2-thienylmethylidene]-2aminothiazole complexes of $\mathrm{Fe}(\mathrm{II}), \mathrm{Co}(\mathrm{II}), \mathrm{Ni}(\mathrm{II}), \mathrm{Cu}(\mathrm{II}), \mathrm{Zn}(\mathrm{II})$ and $\mathrm{Cd}(\mathrm{II})$. Acta Chim. Slov., 48, 257-264.

3. Chandra, S., and Kumar, U. (2005) Spectral and magnetic studies on manganese(II), cobalt(II) and nickel(II) complexes with Schiff bases. Spectrochim. Acta A, 61A, 219-227.

4. Iqbal, J., Tirmizi, S. A., and Watto, F. H. (2006) Biological properties of chloro-salicylidene aniline and its complexes with Co(II) and Ni(II). Turk J. Biol., 30, 1-4.

5. Bagihalli, G. B., Patil, S. A., and Badami, P. S. (2009) Synthesis, physicochemical investigation and biological studies of $\mathrm{Zn}(\mathrm{II})$ complexes with 1,2,4-triazole Schiff bases. J. Iran Chem. Soc., $6,259-270$. 
6. Mahajan, K., Fahmi, N., and Singh, R. V. (2007) Synthesis, characterization and antimicrobial studies of Sb(III) complexes of substituted thioimines. Indian J. Chem., 46A, 1221-1225.

7. Sharma, K., Singh, R., Fahmi, N., and Singh, R.V. (2010) Microwave assisted synthesis, characterization and biological evaluation of palladium and platinum complexes with azomethines. Spectrochim. Acta A, 75, 422-428.

8. Mohanan, K., Kumari, B. S., and Rijulal, G. (2008) Microwave assisted synthesis, spectroscopic, thermal and antifungal studies of some lanthanide(III) complexes with a heterocyclic bishydrazone. J. Rare Earths, 26, 16-21.

9. Sun, Y., Machala, M.L., and Castellano, F.N. (2010) Controlled microwave synthesis of Ru ${ }^{\mathrm{II}}$ synthons and chromophores relevant to solar energy conversion. Inorg. Chim. Acta, 363, 283287.

10. Garg, R., Saini, M.K., Fahmi, N., and Singh, R.V. (2006) Spectroscopic and biochemical studies of some manganese(II), oxovanadium(V) and dioxovanadium(VI) complexes S/O and N donor agents synthesized under microwave conditions. Trans. Met. Chem., 31: 362-371.

11. Mahajan, K., Swami, M., and Singh, R.V. (2009) Microwave synthesis, spectral studies, antimicrobial approach and coordination behavior of antimony(III) and bismuth(III) compounds with benzothiazoline. Russ. J. Coord. Chem., 35, 179-185.

12. Dubey, R.K., Dubey, U.K., and Mishra, C.M. (2008) Synthesis and physicochemical characterization of some Schiff base complexes of chromium(III). Indian J. Chem., 47, 12081212.

13. Mishra, A.P., Sharma, N., and Jain, R., (2011) Synthesis and structure of some novel Schiff base complexes with $\mathrm{Cu}(\mathrm{II})$ and $\mathrm{Ni}(\mathrm{II})$. J. Indian. Chem. Soc., 88, 1429-1434.

14. Ourari, A., Ourari, K., Moumeni, W., and Sibous, L. (2006) Unsymmetrical tetradentate Schiff base complexes derived from 2,3-diphenol and salicylaldehyde or 5-bromosalicylaldehyde. Trans. Met. Chem., 31, 169-175.

15. Raman, N., Raja, S. J., Joseph, J., and Raja, J.D. (2007) Synthesis, spectral characterization and DNA cleavage study of heterocyclic Schiff base metal complexes. J. Chil. Chem. Soc., 52, 1138-1141.

16. Nakamoto, K. (1998) Infrared and Raman Spectra of Inorganic and Coordination Compounds, $5^{\text {th }}$ ed. John Wiley and Sons, Part A \& B, New York.

17. Mishra, A.P., Mishra, R.K., and Shrivastava, S.P. (2009) Structural and antimicrobial studies of coordination compounds of $\mathrm{Vo}(\mathrm{II}), \mathrm{Co}(\mathrm{II}), \mathrm{Ni}(\mathrm{II})$ and $\mathrm{Cu}(\mathrm{II})$ with some Schiff bases involving 2-amino-4chlorophenol. J. Serb. Chem. Soc., 74, 523-535.

18. Abdallah, S.M., Zyed, M.A., and Mohamed, G.G. (2010) Synthesis and spectroscopic characterization of new tetradentate Schiff base and its coordination compounds of NOON donor atoms and their antibacterial and antifungal activity. Arabian J. Chem., 3, 103-113.

19. Neelakantan, M.A., Marriappan, S.S., Dharmaraja, J., Jeyakumar, T., and Muthukumaran, K. (2008) Spectral, XRD, SEM and biological activities of transition metal complexes of polydentate ligands containing thiazole moiety. Spectrochim. Acta, 71A, 628-635.

20. Lever, A.B.P. (1984) Inorganic Electronic Spectroscopy, 2nd Ed. Elsevier, New York.

21. Chandra, S., Jain, D., Sharma, A.K., and Sharma, P. (2009) Coordination modes of a Schiff base pentadentate derivative of 4-aminoantipyrine with cobalt(II), nickel(II) and copper(II) metal ions: synthesis, spectroscopic and antimicrobial studies. Molecules, 14, 174-190.

22. Mohamed, G.G., Omar, M.M., and Hindy, A.M. (2006) Metal complexes of Schiff bases: preparation, characterization and biological activity. Turk J. Chem., 30, 361-379.

23. Hathaway, B.J. (1987) Comprehensive Coordination Chemistry, Vol. 5, Pergamon Press U.K.

24. Sujamol, M.S., Athira, C.J., Sindhu, Y., and Mohanan, K. (2010) Synthesis, spectroscopic characterization, electrochemical behavior and thermal decomposition studies of some transition metal complexes with an azo derivative. Spectrochim. Acta, 75A, 106-112. 
25. Soliman, A.A., and Mohamed, G.G. (2004) Study of the ternary complexes of copper with salicylidene-2-aminothiophenol and some amino acids in the solid state. Thermochim. Acta, 421, 151-159.

26. Wang, Y.F., Liu, J.F., Xian, H.D., and Zhao, G.L. (2009) Synthesis, crystal structure and kinetics of thermal decomposition of the nickel(II) complex of the Schiff base 2-[(4methylphenylimino)methyl]-6-methoxyphenol. Molecules, 14, 2582-2593.

27. Makode, J.T., Yaul, A.R., Bhadange, S.G., and Aswar, A.S. (2009) Physicochemical characterization, thermal and electrical conductivity studies of some transition metal complexes of bis-chelating Schiff base, Russ. J. Inorg. Chem., 54, 1372-1377.

28. Mishra, A.P., and Pandey, L.R. (2005) Synthesis, characterization and solid state structural studies of oxovanadium(IV)-O,N donor schiff base chelates, Indian J. Chem., 44, 94-97.

29. Singh, V. P., Katiyar, A., and Singh, S. (2008) Synthesis, characterization of some transition metal(II) complexes of acetone p-amino acetophenone salicyloyl hydrazone and their antimicrobial activity. Bio Metals, 21, 491-498.

30. Chohan, Z. H. (1999) $\mathrm{Ni}(\mathrm{II}), \mathrm{Cu}(\mathrm{II})$ and $\mathrm{Zn}$ (II) metal chelates with some thiazole derived Schiff-bases: their synthesis, characterization and bactericidal properties. Metal Based Drugs, 6, 75-79.

31. Mohamed, G. G., Omar, M. M., and Ibrahim, A. A. (2009) Biological activity studies on metal complexes of novel tridentate Schiff base ligand. Spectroscopic and thermal characterization. Eur. J. Med. Chem., 44, 4801-4812.

32. Chohan, Z. H., Munawar, A., and Supuran, C. T. (2001) Transition metal ion complexes of Schiff bases synthesis, characterization and antibacterial properties. Metal Based Drugs, 8, 137143. 